Meta

Journal des traducteurs

Translators' Journal

\title{
Creatures of Habit? What Translators Usually Do with Words
}

\section{Dorothy Kenny}

Volume 43, numéro 4, décembre 1998

L'approche basée sur le corpus

The Corpus-based Approach

URI : https://id.erudit.org/iderudit/003302ar

DOI : https://doi.org/10.7202/003302ar

Aller au sommaire du numéro

Éditeur(s)

Les Presses de l'Université de Montréal

ISSN

0026-0452 (imprimé)

1492-1421 (numérique)

Découvrir la revue

Citer cet article

Kenny, D. (1998). Creatures of Habit? What Translators Usually Do with Words. Meta, 43(4), 515-523. https://doi.org/10.7202/003302ar

\section{Résumé de l'article}

Cet article se concentre sur certains des défis méthodologiques et théoriques de l'étude de l'"assainissement" des textes traduits par l'analyse de la prosodie sémantique. L'hypothèse principale est que le vocabulaire des textes cibles est généralement plus restreint que celui de l'original; il en résulte ce que nous appelons des "versions assainies de l'original". 


\title{
CREATURES OF HABIT? WHAT TRANSLATORS USUALLY DO WITH WORDS
}

\author{
DOROTHY KENNY \\ Dublin City University, Dublin, Ireland
}

\begin{abstract}
Résumé
Cet article se concentre sur certains des défis méthodologiques et théoriques de l'étude de l'«assainissement» des textes traduits par l'analyse de la prosodie sémantique. L'hypothèse principale est que le vocabulaire des textes cibles est généralement plus restreint que celui de l'original; il en résulte ce que nous appelons des «versions assainies de l'original».
\end{abstract}

\begin{abstract}
This paper focuses on some of the methodological and theoretical challenges presented by the investigation of "sanitisation" in translated texts through the analysis of semantic prosody. The main hypothesis is that target texts tend to use toned down vocabulary compared with their sources, and that this results in the creation of a "sanitised version of the original."
\end{abstract}

\begin{abstract}
The creative potential of language is undeniable, but the concordances to a corpus remind us forcibly that in most of our utterances we are creatures of habit, immensely predictable, rehearsing the same old platitudes and the same old clichés in almost everything we say. If it were not so, language would become unworkable. Humankind cannot bear very much creativity.
\end{abstract}

(Hanks 1996: 85)

\section{INTRODUCTION}

If there is one thing that corpus linguistics has revealed about language, it is that much of what we say and write in our own language is both routine and predictable because of what we and others have already said and written. Routine is not a bad thing, however. It is what allows the creative use of language to be identified as such. In Hanks's (1996) words: "we need to say precisely what the conventions of use are before we can say how they are used and exploited to create meanings." But if the tolerance for creativity is supposedly limited amongst language users in general, translators, or perhaps more fairly translation markets, must have a special claim to linguistic conservatism. The moulding of translations so they reflect what is routine in the target language is known as normalisation, and this paper sets out to describe how corpora and the tools of corpus linguistics can be brought to bear on the investigation of normalisation in translated texts. I will stress the need for both monolingual and bilingual comparative corpus studies in investigating normalisation, and suggest how similar methods could also be used to explore a related issue, that of "sanitisation" - the suspected adaptation of a source text reality to make it more palatable for target audiences. The

Meta, XLIII, 4, 1998 
paper concludes with a brief description of a project that will attempt to provide empirical evidence for the features of translation hypothesised in the paper.

\section{USING CORPORA TO INVESTIGATE LEXICAL NORMALISATION IN TRANSLATED TEXTS}

Among her proposed universals of translation, Baker (1997: 183) includes normalisation, "a tendency to exaggerate features of the target language and to conform to its typical patterns." Normalisation, she suggests, "is most evident in the use of typical grammatical structures, punctuation and collocational patterns or clichés" (1997). Evidence of normalisation at the lexical level has been provided by translation scholars such as Toury (1980), Vanderauwera (1985) and Malmkjær (this volume). Toury (1980: 130) describes how binomials, a characteristic feature of Hebrew texts, are used to a greater extent in texts translated into Hebrew than in texts originally written in that language; Vanderauwera (1985: 108) observes from a study of some fifty novels translated from Dutch into English that "translators of Dutch fiction exhibited reserve in rendering unusual and mannered imagery and word choice in the target text;" and Malmkjær (this volume) demonstrates how, in multiple translations into English of a single Danish source text, the majority of translators produce a lexically conventional target language text, despite the fact that the original text contravenes norms for Danish.

All three studies suggest useful ways of pursuing the question of normalisation at the lexical level. Toury's approach is essentially monolingual contrastive: the features of text translated into Hebrew are made out against a backdrop of a body of texts originally written in Hebrew. This is an approach advocated by Baker (1995) who uses the term comparable corpus for a structured electronic collection of texts originally written in a particular language, alongside texts translated into that same language. LaviosaBraithwaite (1996: 161) proposes the use of just such a monolingual English comparable corpus to investigate normalisation at the level of collocation. ${ }^{1}$ She hypothesises that texts translated into English will "have a significantly lower frequency of collocational clashes leading to intentional irony or ad hoc/non-institutionalised metaphors" than will comparable texts originally written in English, and suggests that KWIC (Key Word in Context) concordancers and Mutual Information (a measure that indicates whether there is a statistically significant association between two words in a text) might be brought to bear on this phenomenon. Laviosa-Braithwaite thus points the way to an at least partly automated investigation of collocational normalisation based on the comparison of translated and original texts in the target language.

Vanderauwera's and Malmkjær's approach, on the other hand, is both monolingual and bilingual contrastive. ${ }^{2}$ They first identify unusual collocations in the source text on the basis of their knowledge of what is normal in texts in the source language (an SL monolingual contrastive phase); then evaluate the conventionality or creativity of the rendered collocation in the target text on the basis of their knowledge of target language norms (a TL monolingual contrastive phase). Finally, they compare the unusual SL/ST collocation with its TL/TT rendition (a bilingual contrastive phase) in order to ascertain whether unconventional SL collocations are rendered in an equally unconventional fashion in the target text, or whether they are somehow normalised. Here the bulk of the analysis is monolingual contrastive, yet the existence of a body of source texts and their translations into a particular target language, in other words a bilingual parallel corpus (see Baker 1995), is a sine qua non for this kind of translation description. Unusual SL collocations can (and should be) identified in the ST using SL-specific criteria alone. The parallel corpus merely provides the link between the collocations identified as worthy of investigation in the SL and those that should be 
investigated in the TL. This is where Translation Studies departs from Contrastive Linguistics in the study of collocation: contrastive linguists tend to focus on L2 collocations that are somehow remarkable from an L1 point of view (see Lehr 1996: 59 ff. on this point). Translation theorists, however, should be concentrating on SL collocations that are remarkable from an SL point of view.

In the examples cited above, translation theorists have largely used their intuition to make judgements about how usual or unusual an SL collocation is, although Malmkjær does confirm her intuitions about TL norms by referring to the corpusbased COBUILD dictionary. In this paper, I will first outline a methodology that seeks to put the identification of unusual SL (and later TL) collocations on a more empirical footing, not because I wish to entirely abandon the use of translation theorists' intuitions but rather so that more worthwhile data can be unearthed in a way that is independent of bilingual contrastive analysis. I then suggest how corpora can be used to investigate one specific collocational phenomenon, semantic prosody, in a bid to find evidence of "sanitisation" in translated texts.

\section{HOW CONTRASTIVE ANALYSIS CAN BE BOTH MONOLINGUAL AND BILINGUAL: AN EXAMPLE}

The methodology relies upon the availability of (i) a parallel corpus of SL texts and their TL translations, (ii) an SL reference corpus, and (iii) a TL reference corpus. Collocations involving selected node words are extracted from the SL part of the parallel corpus and evaluated against the backdrop of the large SL reference corpus in order to ascertain their (un)conventionality. (The selection of nodes worth investigating in the first place is not a trivial matter, although we will not elaborate on this point here.) A particular collocation may be deemed to be unusual on the basis of its very low frequency of occurrence, but caution is required here: if two words co-occur once in a thirty-thousand word English ST in the parallel corpus, we cannot say very much about the unusualness of this collocation - the sample is simply too small to allow any conclusions to be drawn. If the same collocation did not occur at all in a reference corpus of, say, one hundred million words of English, then we might be able to say on the basis of the absolute frequency of occurrence of this collocation that it is indeed unusual. This example underlines the importance of reference corpora to Translation Studies. Since most translation scholars are not in a position to build corpora that are large enough to justify any statements about the frequency of anything but the most common words or collocations, we have to rely on existing, far more substantial resources such as the British National Corpus (one hundred million words) or the Cobuild Bank of English (over three hundred million words, and growing) to validate our claims. Translation scholars are not alone in this: Stubbs (1996: 69-70) stresses the importance of comparative corpus studies in areas not related to translation, maintaining that "findings should always be compared across different corpora, in order to know what is normal and what is characteristic of a specialised corpus." Relative frequencies of cooccurrence and measures such as Mutual Information can also be used in determining just how unusual or unexpected a particular collocation is.

It may be helpful to introduce an example at this point. The following excerpt is particularly interesting because of the collocation "three-cornered glance," a phrase that appears in Lesley Glaister's novel Digging to Australia, and one that the translator into German, Hans-Christian Oeser, considered unusual enough to warrant an equally unconventional compound word Dreiecksblick (literally a "triangular glance") in the German text: 
Bob's eyes flickered over me, a brief three-cornered glance, a check for progress. I felt like some sort of time-bomb. Thirteen now, about to go off.

(Glaister 1992: 38)

Bob musterte mich aus den Augenwinkeln, ein kurzer Dreiecksblick, ein Abschätzen meiner Fortschritte. Als ob ich eine Zeitbombe wäre. Nun schon dreizehn, kurz vor der Explosion.

(Glaister 1995: 54 translated by H. C. Oeser)

The scene in the novel is one in which a father, mother and their pre-pubescent daughter are doing their daily gym exercises naked. Interpreting the unexpected collocation "three-cornered glance" calls for extra effort on the reader's behalf. Readers may even be forced to trace the same triangular movement with their own eyes before they realise that the father in the story is scanning his daughter's pubic area and chest. Unusual collocations can thus cause an abrupt interruption of a relatively smooth reading process, but undoubtedly add to the reading experience by forcing readers to be less complacent in order to engage more actively with the text.

Such interruptions are reminiscent of what Sinclair (1987: 324) calls switch points. These are points in texts where readers or listeners are forced to abandon one mode of interpretation in favour of another. The default mode of interpretation is the one specified by the idiom principle, according to which (1987: 320):

a language user has available to him or her a large number of semi-preconstructed phrases that constitute single choices, even though they might appear to be analysable into segments.

Habitual collocations are one important manifestation of the idiom principle. The idiom principle contrasts with the open choice principle which reflects the view that text is built up and interpreted using a "slot-and-filler" approach (1987: 319-320):

At each point where a unit is completed (a word or a phrase or a clause), a large range of choice opens up, and the only restraint is grammaticalness.

While language users normally apply the idiom principle in their interpretation of texts, Sinclair (1987: 324) holds that:

Whenever there is good reason, the interpretive process switches to the open choice principle, and quickly back again. Lexical choices which are unexpected in their environment will presumably occasion a switch...

(emphasis mine)

Returning to the passage from the Glaister novel cited above, we can say that the published German translation achieves a similar effect to the original by providing an analogous switch point between the two modes of textual interpretation.

Switches such as this are an effective literary device, but they are rarely tolerated by editors of translations, who often feel obliged to make target texts conform to target language norms. The urge to normalise is most probably due to editors' awareness of the precarious position of translated literature in many markets. In the United States, for example, translations account for a mere three per cent of total book production (Rectanus 1990: 3), and those few literary texts that are translated tend to toe the target culture line. Drawing on his study of translated German literature in the USA, Rectanus (1990: 5) suggests an association between the assimilation of the foreign text and its commercial success, a factor that must bear on the minds of editors, publishers and translators alike:

One of the results of licensing literature in an international literary marketplace is the decontextualization of the text and its assimilation into the foreign context. The foreign 
origin of the text often becomes superfluous or functions merely as exotic packaging. The degree to which the text can be assimilated into the foreign context of mass and/or subcultures frequently determines its market acceptance and popular reception.

Vanderauwera (1985: 37), in her study of Dutch literature translated into English, makes a similar point: the foreign text is usually allowed to be exotic only in its packaging, not in its linguistic features.

While the purpose and packaging (jacket, introduction) of the translation are "metaliterary" and pretend to promote "great" representativeness of Dutch literature, the actual target text is often adjusted or smoothened with a view to the audience's reading habits.

There is thus a link between the dynamics of the literary marketplace and the linguistic features, such as collocational patterns, of target texts. Whereas in the past socalled "linguistic" approaches to translation have been criticised for their inability to say anything about the wider cultural context in which translation occurs, ${ }^{3}$ I would like to suggest here that a careful study of collocational patterns in translated text can shed light on the cultural forces at play in the literary marketplace, ${ }^{4}$ and vice versa. Culture and language are inextricably bound up in one another, and it makes no sense to suggest that cultural and linguistic approaches to the study of translation can be mutually exclusive.

Let us return to the "three-cornered glance" from the Glaister novel cited above in an effort to show how reference corpora can be useful in evaluating source texts. In this particular case, translator and editor battled it out: the editor preferred a more conventional wording such as "Bob musterte mich verstohlen/heimlich/flüchtig aus den Augenwinkeln" [Bob examined me stealthily/secretly/fleetingly out of the corner of his eye]. However, the translator preferred the version that was eventually published, on the grounds that an unconventional ST wording should be matched by an equally unconventional TT wording. It would seem that recourse to a reference corpus of English supports the translator's claim that the collocation in question is indeed unusual. Using the CobuildDirect corpus, a corpus of some fifty million words of contemporary British and American English that can be accessed using the World-Wide Web, we see that there is a significant association between the word "glance" and the modifiers "sidelong," "sidewise," "cursory," "furtive," "upward," "backwards," etc. but that there is no instance of "three-cornered" modifying "glance." Likewise, "three-cornered" is an attribute imputed to "contests," "fights" and the eponymous "hat" of Massine's ballet, but not to "glances."

The searches carried out in this case were rather informal, and a more rigorous investigation of the nodes "glance" and "three-cornered" is undoubtedly called for, but the point is made nonetheless - that a reference corpus in the language of the source text can serve as a useful backdrop to the evaluation of collocations in the text. In the same way, a corpus of contemporary German language can serve as a yardstick by which one can measure the originality of the translator's solution. Again, the corpora of the Institut für deutsche Sprache in Mannheim can be accessed remotely by researchers, and significant collocates for the component parts ${ }^{5}$ of the ad hoc compound Dreiecksblick investigated. A cursory investigation of the nodes Dreieck* (triangle/triangular) and Blick (glance) in a group of corpora containing about twenty million words shows their juxtaposition in a compound word to be as unexpected as was the original cooccurrence of "three-cornered" with "glance." This, then, is a case where normalisation has not occurred in translation, despite the intervention of an editor adhering to target norms. 


\section{NODE SELECTION AND THE SPECIAL CASE OF SEMANTIC PROSODIES}

So far I have attempted to demonstrate how same-language reference corpora can be used to place source and target text collocations on a scale of originality/conventionality. There are accepted statistical techniques for measuring the "conventionality" of a collocation (see, for example, work by Church et al. 1991). One issue that deserves more attention, however, is the selection of interesting nodes for collocation analysis. We do not intend to address this question in any detail here. Suffice it to say that, unlike lexicographers, who are primarily interested in recurring collocations, translation scholars investigating normalisation at the level of collocation are necessarily interested in once-off or idiosyncratic collocations. We are looking, in the first instance, for the collocationally unlikely. A second point worth making is that it is highly desirable that the selection of nodes that appear to feature in unlikely collocations be automated as much as possible. Although it seems something of a tall order, automating the selection of nodes would go some way towards ensuring systematic and exhaustive treatment of the data in a parallel corpus.

One potentially interesting method of selecting nodes relies on the idea of semantic prosodies. A semantic prosody, according to Louw (1993: 157) is a "consistent aura of meaning with which a form is imbued by its collocates." The seemingly innocuous phrasal verb "set in," for example, becomes imbued with a negative aura because of its habitual collocation with words like "rot," "decay," and "rigor mortis" (see Sinclair 1991: 74-75). A writer may use the semantic prosody of a word to achieve an ironic effect: if one were to write that "happiness had set in," the clash between the negative prosody of the verb "set in" and the normally positive associations of the word "happiness" might force the reader to switch to another mode of interpretation. Departures from expected profiles of semantic prosodies are thus a special case of unusual collocation and could provide interesting data upon which to base a study of normalisation in translated texts. If it were shown that such source text collocational clashes were rendered in the target text by wordings that contained no such clashes, this could then lend weight to the hypothesis that translators tend to replace unconventional ST collocations with conventional TL ones. But semantic prosodies (unlike what are traditionally called the "connotations" of words) are "largely inaccessible to human intuition about language" and "cannot be retrieved reliably through introspection" (Louw 1993: 157). In order to identify such collocational clashes in the source text, we therefore need access to a large reference corpus of SL texts, which provides the backdrop against which we interpret the ST collocation in hand. Again, comparative monolingual corpus studies are indispensable.

\section{SEMANTIC PROSODIES AND "SANITISATION"}

We need not necessarily be investigating departures from expected collocational patterns for the concept of semantic prosody to be of use to us in Translation Studies. There are instances, for example, where the reader of an original text and its translation may feel that the translation is somehow tamer than the original, or that it paints a less bleak picture of a situation than did the original. It is often difficult, however, to say precisely why one has this feeling. One might be able to put one's finger on particular points in the text where certain passages have been toned down (see van Doorslaer's (1995: 249) comments on the translation of one Flemish novel into German), but one may be left with a vague suspicion that there is more to it than that; that there is somehow a different attitude dispersed over the pages of the target text. I suggest here that by studying the vocabulary of a source text specifically the prosodies of certain lexical 
items against the backdrop of an SL reference corpus, it may be possible to discover traits of words used in the source text that are missing in the target text. Take, for example, the word "giro" in the following excerpt from Gerry Conlon's autobiography Proved Innocent: ${ }^{6}$

I was a mad gambler then and one day I picked up my uncle's Giro, cashed it and had it on a dog which got beat. Nothing was said, but he must have been terribly hurt knowing what I'd done.

(Conlon 1991: 44)

To speakers of British English, "giro" is an informal word for an unemployment or income support cheque. The word as used here is unremarkable, but it is a clear indication that Conlon has stolen, not just from a member of his own family, but from one who can ill afford the loss. The denotation of "giro" is clear, and despite the association of giros with unemployment, a state that is normally negatively evaluated, the word would not seem to have any intrinsically negative connotations. If we consider the lexical company that the word "giro" keeps, however, we can make a good case for saying that it has negative semantic prosody. Consider the following concordance lines taken from the CobuildDirect: ${ }^{7}$

in London, 1038133 Charity 263710. Giro 5012252 . I thought the bank giro system was supposed to make the use of the "personal-issue giro" the money order designed for working flat-out to supplement her giro, she was expected to do what more likely to come from a Giro than a wage packet. special DSS handout can wait until Giro day, and the meths are on me. travellers have been described as giro gypsies, scroungers and parasites, How defiant giro hippies milk system for cash chain running from ear to ear and giro money stuffed in his mouth

The first three instances of "giro" listed here obviously refer to the money transfer system operated by financial institutions. The other instances refer more specifically to cheques issued to unemployed people. What is interesting about the instances of the more specific sense is the environment in which mention is made of "giro:" even given such a small number of concordance lines it is clear that the word "giro" is accompanied by words that have very negative connotations ("gypsies," "scroungers," "handout," "meths," etc.). We can surmise that "giro" has negative semantic prosody because it is tainted by its collocates. All this makes the translation of this excerpt into German all the more surprising:

Ich war damals ein besessener Spieler, und eines Tages klaute ich das Scheckheft meines Onkels, schrieb einen dicken Scheck aus, löste ihn ein und setzte das Geld auf einen Hund, der verlor. Mein Onkel muß schrecklich betroffen und enttäuscht gewesen sein, als sich herausstellte, was ich getan hatte.

(Conlon 1994: 68 translated by C.G. Lecaux and J. Honnef)

[I was a mad gambler then and one day I stole my uncle's chequebook, wrote a fat cheque, cashed it and put the money on a dog that lost. My uncle must have been terribly affected and hurt when what I had done was discovered.]

The German translation can be criticised on a number of fronts: the translators seem not to have understood the denotation of the English "giro," and because they interpret the word as meaning chequebook, they then have to fabricate the writing of a (fat) cheque, in order to introduce into the discourse something that can be cashed. But another criticism could be that the target text paints a picture of a social reality that is far more comfortable than that of the original text. Conlon's uncle is a recipient of social welfare in the English text; in German he is a provider of funds. The mention of 
the word "giro" in the source text means that Conlon's family are stigmatised in the same way as other members of society who rely on social welfare, but there is no such stigmatisation in the target text: unsurprisingly, concordance lines for the words Scheck (cheque) and Scheckheft (chequebook) extracted from a German reference corpus (the LIMAS-Korpus in Mannheim) refer largely to financial transactions and have a neutral tone.

The "giro" example is perhaps a little obvious, but it illustrates the point that source text words with negative semantic prosodies that are at best vaguely perceptible to readers can be replaced in the target text by more neutral vocabulary. And while it may be difficult for a reader of both the source and target text to pinpoint exactly where these subtle changes are made, the overall effect can be that target texts become somewhat "sanitised" versions of the original. Pursuing this line of argumentation would mean investigating the semantic prosodies of as many vocabulary items as possible in various source texts and their translations; precisely the kind of research that can be undertaken once one has access to a parallel corpus and reference corpora for both the source and target languages.

\section{WHERE DO WE GO FROM HERE?}

The ideas mooted above are stil in embryonic form - there is no suggestion that the examples cited are in any way representative of translation from English into German. There is an obvious need therefore for more empirical research using parallel and monolingual comparable corpora. One project that is attempting to make up some of the deficit in empirical research into translation is based at Dublin City University and UMIST, Manchester. Under the supervision of Mona Baker, a parallel corpus of approximately one million words from German literary fiction and its translation into English is being compiled. The aim is to extract unusual or idiosyncratic collocations in the German originals and assess the creativity of their renditions in English. The project will rely on the substantial resources of the Mannheimer Korpora and the British National Corpus for data about typical collocational patterns in German and British English. Once the parallel German/English corpus has been completed, other research projects that could make use of such a resource can be envisaged. One such project has already been suggested above: an exploration of what happens in translation to vocabulary items with negative (or positive, or even neutral) semantic prosodies. Another obvious study would involve using the parallel corpus to see if translators have tried, for example, to compensate for the loss of collocational creativity in the target text (see Harvey 1995). As has been shown time and time again in corpus linguistics, a new resource can give impetus to new research. The challenge is to know what questions to ask of a translation-oriented corpus, and how to ask them.

\section{Notes}

1. In this paper the term "collocation" is taken to mean "the occurrence of two or more words within a short space of each other in a text" (Sinclair 1991: 170). Such a definition allows for once-off or rare cooccurrences of words as well as habitual ones to be called "collocations." For the time being, no particular constraints are being put on the relationships between the words involved in a collocation.

2. The use here of the expression "bilingual contrastive" is in no way intended to suggest that the studies concerned are excursions into the field of contrastive linguistics. Contrastive linguists use collections of source and target texts (parallel corpora) as an empirical source of data on the way different languages typically give expression to the same extralinguistic reality. Shifts from a common linguistic ground are usually explained in terms of the structural or other properties of the two languages involved (see, for example, the collection of papers in Aijmer et al. 1996). Translation scholars, on the other hand, are more interested in 
features of translations that can be explained in terms of the "nature and pressures of the translation process" (Baker 1997: 177), rather than the contrasting language systems involved.

3. Critics of linguistic approaches to translation, however, seem to approve of only one kind of linguistics, American generative linguistics (see, for example, Gentzler 1993), and to exclude other schools like the British tradition (see Stubbs 1996: Chapter One).

4. For an illuminating discussion of how collocation serves as a vehicle of cultural transmission within a single culture, see Stubbs 1996.

5. Lehr (1996: 84) holds that ad hoc German compounds must be split into their component parts before statements can be made about the frequencies of types (and presumably collocational patterns of types) in texts.

6. I am grateful to Fionnuala Johnston, who brought this example and others in the same text to my attention.

7. For the sake of clarity, we have omitted concordances for the bicycle race sense of "giro," as in Giro d'Italia, of which this search unearthed four instances.

\section{REFERENCES}

AIJMER, K., ALTENBERG, B. and M. JOHANSSON (Eds) (1996): Languages in Contrast: Papers from a Symposium on Text-based Cross-linguistic Studies, Lund, Lund University Press.

BAKER, M. (1995): "Corpora in Translation Studies: An Overview and Some Suggestions for Future Research", Target, 7 (2), pp. 223-243.

BAKER, M. (1997): "Corpus-based Translation Studies: the Challenges that Lie Ahead", H. Somers (Ed.), Terminology, LSP and Translation: Studies in Language Engineering in Honour of Juan C. Sager, Amsterdam, John Benjamins, pp. 175-186.

CHURCH, K., GALE, W., HANKS, P. and D. HINDLE (1991): "Using Statistics in Lexical Analysis", U. Zernik (Ed.), Lexical Acquisition: Exploiting On-Line Resources to Build a Lexicon, Hillsdale N.J., Lawrence Erlbaum Associates Inc., pp. 115-164.

CONLON, G. (1991): Proved Innocent, London, Penguin Books.

CONLON, G. (1994): Im Namen des Vaters, translated by C.G. Lecaux and J. Honnef, Bergisch Gladbach, Bastei.

FIRTH, J. R. (1957): "Modes of Meaning", Papers in Linguistics 1934-1951, Oxford, Oxford University Press, pp. 190-215.

GENTZLER, E. (1993): Contemporary Translation Theories, London and New York, Routledge.

GLAISTER, L. (1992): Digging to Australia, London, Secker and Warburg.

GLAISTER, L. (1995): Buddeln bis Australien, translated by H.C. Oeser, Zürich, Diogenes.

HANKS, P. (1996): "Contextual Dependency and Lexical Sets", International Journal of Corpus Linguistics, 1 (1), pp. 75-98.

HARVEY, K. (1995): "A Descriptive Framework for Compensation", The Translator, 1 (1), pp. 65-86.

LAVIOSA-BRAITHWAITE, S. (1996): "Comparable Corpora: Towards a Corpus Linguistic Methodology for the Empirical Study of Translation", Thelen, M. and B. Lewandowska-Tomaszczyk (Eds), Translation and Meaning, Part 3, pp. 153-163.

LEHR, A. (1996): Kollokationen und maschinenlesbare Korpora: Ein operationales Analysemodell zum Aufbau lexikalischer Netze, Tübingen, Niemeyer.

LOUW, Bill (1993): "Irony in the Text or Insincerity in the Writer? The Diagnostic Potential of Semantic Prosodies", Baker, M., Francis, G. and E. Tognini-Bonelli (Eds), Text and Technology: In Honour of John Sinclair, Amsterdam, John Benjamins, pp. 157-176.

MALMKJÆR, K. (this volume): "Love thy Neighbour: Will Parallel Corpora Endear Linguists to Translators?".

RECTANUS, M. W. (1990): German Literature in the United States: Licensing Translations in the International Marketplace, Wiesbaden, Otto Harrassowitz.

SINCLAIR, J. (1987): "Collocation: a Progress Report", Steele, R. and T. Treadgold (Eds), Language Topics: Essays in Honour of Michael Halliday, Amsterdam, John Benjamins, pp. 319-331.

SINCLAIR, J. (1991): Corpus, Concordance, Collocation, Oxford, Oxford University Press.

STUBBS, M. (1996): Text and Corpus Analysis, Oxford and Cambridge Mass., Blackwell.

TOURY, Gideon (1980): In Search of a Theory of Translation, Tel Aviv, The Porter Institute for Poetics and Semiotics.

VANDERAUWERA, R. (1985): Dutch Novels Translated into English: The Transformation of a "Minority" Literature, Amsterdam, Rodopi.

VAN DOORSLAER, L. (1995): "Quantitative and Qualitative Aspects of Corpus Selection in Translation Studies", Target, 7 (2), pp. 245-260. 